\title{
Algorithms imaging tests comparison following the first febrile urinary tract infection in children
}

\author{
María M. Tombesi ${ }^{a}$, M.D., Laura F. Alconcher ${ }^{b}$, M.D., Lucas Lucarellib , M.D. and Agustina Ciccioli ${ }^{a}$, M.D.
}

\begin{abstract}
Objectives. To compare the diagnostic sensitivity, costs and radiation doses of imaging tests algorithms developed by the Argentine Society of Pediatrics in 2003 and 2015, against British and American guidelines after the first febrile urinary tract infection (UTI).

Population and Methods. Inclusion criteria: children $\leq 2$ years old with their first febrile UTI and normal ultrasound, voiding cystourethrography and dimercaptosuccinic acid scintigraphy, according to the algorithm established by the Argentine Society of Pediatrics in 2003, treated between 2003 and 2010. The comparisons between algorithms were carried out through retrospective simulation.

Results. Eighty (80) patients met the inclusion criteria; 51 $(63 \%)$ had vesicoureteral reflux (VUR); $6 \%$ of the cases were severe. Renal scarring was observed in 6 patients $(7.5 \%)$. Cost: ARS 404,000. Radiation: 160 millisieverts. With the Argentine Society of Pediatrics' algorithm developed in 2015, the diagnosis of 4 VURs and 2 cases of renal scarring would have been missed. The cost of this omission would have been ARS 301,800 and 124 millisieverts of radiation. British and American guidelines would have missed the diagnosis of all VURs and all cases of renal scarring, with a related cost of ARS23,000 and ARS40,000, respectively and 0 radiation.

Conclusion. Intensive protocols are highly sensitive to VUR and renal scarring, but they imply high costs and doses of radiation, and result in questionable benefits.

Key words: urinary tract infections, algorithms, diagnostic imaging, vesicoureteral reflux, renal scarring.
\end{abstract}

http:/ / dx.doi.org/10.5546/ aap.2017.eng.370

To cite: Tombesi MM, Alconcher LF, Lucarelli L, et al. Algorithms imaging tests comparison following the first febrile urinary tract infection in children. Arch Argent Pediatr 2017;115(4):370-373.

a. Service of Diagnostic Imaging.

b. Unit of Pediatric Nephrology. Hospital Interzonal Dr. José Penna, Bahía Blanca, Argentina.

E-mail address:

María M. Tombesi, M.D., mariamarcelatombesi8@gmail.com

Funding: None.

Conflict of interest: None.

Received: 7-28-2016

Accepted: 12-29-2016

\section{INTRODUCTION}

There is no consensus on the optimal imaging strategy after the first febrile urinary tract infection (UTI). In part, this is due to the lack of certainties about the long-term clinical significance of vesicoureteral reflux (VUR) and UTI-associated renal scarring. Currently, we know that in a high percentage of children with renal compromise previously attributed to pyelonephritis and VUR, this condition is actually congenital. Moreover, after their first febrile UTI episode, most children have a good prognosis. ${ }^{1-4}$

In the last decade, there has been a proliferation of algorithms that coincided in a drastic reduction of imaging studies. There is a marked variability as regards sensitivity and specificity for the detection of abnormalities, as well as a great difference in health-related costs and radiation exposure. ${ }^{5-7}$ In Argentina, the algorithm by the Argentine Society of Pediatrics (SAP) in 2003, recommending an ultrasound, a voiding cystourethrography (VCUG) and a late dimercaptosuccinic acid (DMSA) scintigraphy for all children $\leq 2$ after the first febrile UTI, was reviewed. ${ }^{8}$ In the most recent consensus by SAP in 2015, it was decided that, after the first febrile UTI with normal kidney and bladder ultrasound scans, the VCUG would be restricted to children $\leq 1$ and the DMSA to patients with VUR, six months after the UTI. ${ }^{9}$

\section{OBJECTIVES}

To compare the diagnostic sensitivity, health-related costs and radiation doses of SAP algorithms from 2003 and 2015, against the British guidelines by the National Institute for Clinical Excellence (NICE) and the current American guidelines after the first febrile UTI.

\section{POPULATION AND METHODS}

Observational and retrospective study. The study analyzed case records from UTI patients treated between 2003 and 2010 at the Unit of Pediatric Nephrology and the Service of Radiology of Hospital Dr. José Penna in Bahía Blanca, Province of Buenos Aires, Argentina.

Inclusion criteria: $\leq 2$ years old with their first febrile UTI episode, with normal kidney 
and bladder ultrasound scans, good response to treatment, assessed by VCUG and late DMSA.

The percentage of detected VURs and their severity was assessed according to the international classification -Grades I, II (low), III (moderate), IV-V (severe)-.${ }^{10}$ DMSAs were considered abnormal if they showed scarring (areas without uptake). The scarring was classified as mild or significant, based on the differential renal function ( $>$ or $\leq 45 \%$, respectively). ${ }^{11}$ Health-related costs were estimated based on average local costs: ultrasound, ARS 550; VCUG, ARS 1500; DMSA, ARS 3000 (1 dollar: ARS 14,50, September 2016).

The radiation dose was reported in millisieverts $(\mathrm{mSv})$, a unit that represents the harmful effect of the exposure to radiation on organs and tissue. The calculation was $1 \mathrm{mSv}$ for each VCUG and DMSA. ${ }^{12}$

The comparison of diagnostic sensitivity, health-related costs and radiation dose among the different protocols was carried out through retrospective simulation. Table 1 compares the imaging strategies to be evaluated. NICE guidelines describe UTIs in terms of typical (good response within $48 \mathrm{~h}$ of treatment) and atypical (no response to antibiotic treatment). ${ }^{6}$ The guidelines of the American Academy of Pediatrics (AAP) recommend a VCUG in cases of recurrent UTI, pathological ultrasound and atypical UTI. ${ }^{7}$ This study only compared the recommendations for typical UTIs. The authorization of the internal Research and Ethics Committees was requested to review case records. Since this was a retrospective study, no informed consent was obtained.

TABLE 1. Comparison of the indication of imaging studies after the first febrile urinary tract infection in children

\begin{tabular}{lccc}
\hline Guidelines & Ultrasound & VCUG & Late DMSA \\
\hline $\begin{array}{l}\text { SAP (2003) } \\
\leq 2 \text { years }\end{array}$ & Yes & Yes & Yes \\
$\begin{array}{l}\text { SAP (2015) } \\
\leq 1 \text { year }\end{array}$ & Yes & Yes & Performed if VUR is detected \\
$>1$ year old & Yes & No & No \\
NICE & Yes & Performed if the ultrasound is pathologic & No \\
$\leq 6$ m.o. & No & No & No \\
$>6$ m.o. & & & No \\
AAP & Yes & Performed if the ultrasound is pathologic & \\
2 m.o. to $\leq 24$ m.o. & & & \\
\hline
\end{tabular}

VCUG: voiding cystourethrography; DMSA: dimercaptosuccinic acid; SAP: Argentine Society of Pediatrics;

NICE: British guidelines from the National Institute for Clinical Excellence; AAP: guidelines from the American Academy of Pediatrics; VUR: vesicoureteral reflux.

TABLE 2. Comparative chart: direct costs, radiation doses, diagnoses and omissions with the implementation of the different imaging guideline. $\mathrm{N}: 80$

\begin{tabular}{|c|c|c|c|c|}
\hline Guidelines & Direct costs & Radiation dose (mSv) & Diagnoses & Diagnostic omission \\
\hline SAP (2003) & ARS 404,000 & 160 & $\begin{array}{l}\text { VUR: } 51 \text { patients } \\
\text { 20: Grades I-II } \\
\text { 26: Grade III } \\
\text { 5: Grade IV } \\
\text { Scarring: } 6 \\
\text { 5 pequeñas } \\
1 \text { significativa }\end{array}$ & 0 \\
\hline SAP (2015) & ARS 301,800 & 124 & $\begin{array}{l}\text { VUR: } 47 \text { patients } \\
\text { 19: Grades I-II } \\
\text { 24: Grade III } \\
\text { 4: Grade IV } \\
\text { Scarring: } 4 \\
2 \text { small } \\
1 \text { significant }\end{array}$ & $\begin{array}{l}\text { VUR: } 4 \text { patients } \\
\text { 1: Grade II } \\
\text { 2: Grade III } \\
\text { 1: Grade IV } \\
\text { 1: Grade IV } \\
\text { Scarring: } \\
2 \text { small }\end{array}$ \\
\hline NICE (2007) & ARS 23,000 & 0 & No VUR or scarring & All VURs and scarrings \\
\hline $\operatorname{AAP}(2011)$ & ARS 40,000 & 0 & No VUR or scarring & All VURs and scarrings \\
\hline
\end{tabular}

SAP: Argentine Society of Pediatrics; NICE: British guidelines from the National Institute for Clinical Excellence;

AAP: guidelines from the American Academy of Pediatrics; VUR: vesicoureteral reflux. 
The differences in costs and radiation doses were analyzed through Friedman and Wilcoxon tests with Bonferroni correction, using SPSS software, version 22 .

\section{RESULTS}

Out of the 188 patients treated for UTI, 80 met the inclusion criteria; 40 of them were female; 46 were younger than 6 months old; 30 were between 7-12 months old; and 4 were older than 12 months old. VUR was detected in 51 patients $(63 \%) ; 47$ of them $<1$ year old. Only $10 \%$ of the VURs were severe. Six patients showed abnormalities in the DMSA (7.5\%); only 1 had significant renal scarring. Table 2 compares the costs, radiation doses, diagnoses and omissions with the implementation of each guideline.

The greatest differences in costs and radiation are seen between the Argentine and NICEAmerican guidelines. The difference between the 2003 and 2015 SAP guidelines, as regards costs and radiation doses, reached statistical significance (Table 3).

Average follow-up of patients with VUR and scarring was 67 months. All 6 patients with scarring had normal growth, blood pressure and renal function, without proteinuria.

\section{DISCUSSION}

The different algorithms showed marked differences as regards the diagnostic sensitivity. By comparing health-related costs and the doses of radiation between the guidelines, statistically significant differences were found.

Diagnostic sensitivity. The significance of VUR and renal scarring, as well as the importance of their diagnosis, has been a controversial

TABLE 3. Comparison between the costs and radiation of the different imaging guidelines

\begin{tabular}{lcccc}
\hline \multirow{2}{*}{$\begin{array}{l}\text { Paired guidelines } \\
\text { Wilcoxon test }\end{array}$} & \multicolumn{4}{c}{ Factor } \\
\cline { 2 - 5 } & \multicolumn{2}{c}{ Cost } & \multicolumn{2}{c}{ Radiation } \\
\cline { 2 - 5 } & z value & variation & z value variation \\
\hline AAP (2011)-NICE (2007) & 17.50 & $-5.831^{\mathrm{b}}$ & 0.00 & $0.000^{\mathrm{a}}$ \\
SAP (2015)-NICE (2007) & 40.50 & $-7.843^{\mathrm{b}}$ & 38.50 & $-7.871^{\mathrm{b}}$ \\
SAP (2003)-NICE (2007) & 40.50 & $-8.037^{\mathrm{b}}$ & 40.50 & $-8.944^{\mathrm{b}}$ \\
SAP (2015)-AAP (2011) & 38.50 & $-7.871^{\mathrm{b}}$ & 38.50 & $-7.871^{\mathrm{b}}$ \\
SAP (2003)-AAP (2011) & 40.50 & $-8.944^{\mathrm{b}}$ & 40.50 & $-8.944^{\mathrm{b}}$ \\
SAP (2003)-SAP (2015) & 16.50 & $-5.387^{\mathrm{b}}$ & 16.50 & $-5.387^{\mathrm{b}}$ \\
\hline
\end{tabular}

\footnotetext{
a There are no statistical differences between the guidelines. ${ }^{b}$ There are highly significant differences between the paired imaging guidelines.

AAP: Guidelines from the American Academy of Pediatrics; NICE: British guidelines from the National Institute for Clinical Excellence; SAP: Argentine Society of Pediatrics.
}

issue. For years, VUR was considered to be the greatest factor in UTI-associated damage, and a significant cause of chronic kidney disease (CKD). Currently, we know that most patients who develop CKD are born with associated kidney dysplasia (non-preventable congenital damage). As a consequence, the stringent screening for VUR in the last 40 years has not changed CKD prevalence levels. There is also evidence that acquired kidney damage is related more to the UTI than to the VUR. ${ }^{4-6}$

Under the 2003 SAP algorithm, no VUR or scarring diagnosis was missed. With the 2015 recommendations, 4 VURs (1 grade II, 2 grade III and 1 grade IV) and 2 cases of small scarring would have gone undiagnosed. By implementing the NICE and American guidelines, all the diagnoses would have been missed.

In our group, a high percentage of VUR was detected which could be explained by the referral of previously diagnosed patients to the nephrology office. However, $90 \%$ of these cases were low grade (only $6 \%$ of VURs were grade IV). Our data is consistent with the results of a recent systematic revision which showed that, after the first febrile UTI, only $2.5 \%$ of VURs were grade IV-V showing the high percentage of children that are subjected to unnecessary tests. ${ }^{1}$ The clinical significance of grades I-III VURs is controversial because VURs have a tendency to resolve spontaneously and there is no evidence that surgery and prophylactic antibiotics can reduce the development of scarring. ${ }^{13}$

The percentage of scarring in our group was lower than that published in other series, probably because only patients with their first UTI and normal ultrasound scans were included. Long-term prognosis seems to be good, with a low risk of hypertension and / or CKD. ${ }^{4}$ Early diagnosis and treatment of UTIs is the strategy that has the highest impact on the prevention of renal scarring.

Health-related costs. Our investigation was limited because only costs of imaging studies, known as "direct health-related costs," could be estimated. It was not possible to determine non healthcare-related costs (transportation of patients, unnecessary use of time and space), indirect costs (absenteeism, productivity loss) or intangible costs, which are difficult to assess (pain, stress, exposure to radiation by technical and medical staff).

Although costs under the NICE and American guidelines are much lower, diagnostic omission 
error is significant. It was recently reported that the implementation of NICE guidelines reduced imaging studies by $77 \%$, but it missed $58 \%$ of abnormalities. Therefore, the authors recommended ultrasound scans in children $<1$ year old. ${ }^{14}$

In Argentina, 750,000 children are born every year, and UTI incidence in children $<2$ years old is $8 \%$ in girls and $2 \%$ in boys. ${ }^{15}$ If we estimate only the cost of tests after the first febrile UTI in children $<2$ years old, according to the 2003 SAP algorithm, the cost would amount to USD 378,750,000. By implementing the new 2015 SAP recommendations, this cost would fall to USD 126,112,500 per year.

Radiation dose. Less intensive protocols imply a lower radiation exposure. In Argentina, the annual dose limit for patients is $1 \mathrm{mSv}$, and there is a recommendation not to exceed $5 \mathrm{mSv}$ in 5 years. Large campaigns are being conducted to raise awareness about the rational use of radiation in children, with a high level of compliance among Argentine pediatric radiologists. The adequate selection of diagnostic methods is promoted, targeting populations at risk, with the aim of minimizing invasive procedures that imply radiation exposure, while maintaining an acceptable sensitivity to detect significant abnormalities. It is important to highlight the importance of ultrasound scans to determine the need for additional tests.

Our data supports the new national consensus. By implementing these guidelines, DMSAs would have been reduced by $56 \%$, VCUG by $25 \%$, radiation dose by $25 \%$ and costs by $27 \%$, with little significant kidney damage and few diagnostic omission errors of VUR.

\section{CONCLUSION}

More intensive protocols have a high sensitivity to detect VUR and renal scarring, but they are related to high healthcare-related costs and considerable doses of radiation resulting in a doubtful benefit.

\section{Acknowledgments}

To Nadia Ripari, M.D. and María Eugenia Elorza, M.D. for their contribution to statistical analysis.

\section{REFERENCES}

1. Shaikh N, Ewing AL, Bhatnagar S, Hoberman A. Risk of renal scarring in children with a first urinary tract infection: a systematic review. Pediatrics 2010;126(6):1084-91.

2. Gordon I, Barkovics M, Pindoria S, Cole TJ, et al. Primary vesicoureteric reflux as a predictor of renal damage in children hospitalized with urinary tract infection: a systematic review and a meta-analysis. J Am Soc Nephrol 2003;14(3):739-44.

3. Marra G, Oppezzo C, Ardissino G, Daccò V, et al. Severe vesicoureteral reflux and chronic renal failure: a condition peculiar to male gender? Data from Italkid project. J Pediatr 2004;144(5):677-81.

4. Salo J, Ikäheimo R, Tapiainen T, Ulhari M. Childhood urinary tract infections as a cause of chronic kidney disease. Pediatrics 2011;128(5):840-7.

5. Prasad MM, ChengEY. Radiographicevaluation of children with febrile urinary tract infection: bottom-up, top-down, or none of the above? Adv Urol 2012;2012:716739.

6. National Institute for Health and Clinical Excellence. Urinary tractinfection in children: diagnosis, treatment and long-term management. London: Stata Press; 2007. Clinical guideline 54. [Accessed on: January 06, 2017]. Available at: https:// www.nice.org.uk/guidance/cg54.

7. Subcommittee on Urinary Tract Infection, Steering Committee on Quality Improvement and Management. Urinary tract infection: clinical practice guideline for the diagnosis and management of the initial UTI in febrile infants and children 2 to 24 months. Pediatrics 2011;128(3):595-610.

8. Grimoldi IA, Amore AI. Infección urinaria. En Ferraris JR, Briones Orfila L, eds. Nefrología Pediátrica. 2.a ed. Buenos Aires: Sociedad Argentina de Pediatría; 2008:407-23.

9. Comité de Nefrología(2011-2013). Nuevas recomendaciones frente a las actuales controversias en infección urinaria. Resumen ejecutivo. Arch Argent Pediatr 2015;113(6):579-81.

10. Medical versus surgical treatment of primary vesicoureteral reflux: a prospective international reflux study in children. J Urol 1981;125(3): 277-83.

11. Pusuwan P, Reyes L, Gordon I. Normal appearances of technetium-99m dimercaptosuccinic acid in children on planar imaging. Eur J Nucl Med 1999;26(5):483-8.

12. Radiation Safety - American College of Radiology. [Accessed on:October 04, 2015]. Availableat: https: / / www. acr.org / Quality-Safety / Radiology-Safety / RadiationSafety.

13. Smellie JM, Barratt TM, Chantler C, Gordon I, et al. Medical versus surgical treatment in children with severe bilateral vesicoureteric reflux and bilateral nephropathy: a randomised trial. Lancet 2001;357(9265):1329-33.

14. McDonald K, Kenney I. Pediatric urinary tract infections: a retrospective application of the National Institute of Clinical Excellence guidelines to a large general practitioner referred historical cohort. Pediatr Radiol 2014;44(9):1085-92.

15. López CR, Gómez Rinesi JF. Tratamiento de la infección urinaria en pediatría. Rev Posgrado VIa Cátedra Med 2003;123:3-13. 